\title{
IGBT-SiC Dual Fed Ground Power Unit
}

\author{
Luca Rovere, Andrea Formentini, Giovanni Lo Calzo, \\ Pericle Zanchetta \\ Dept. of Electrical and Electronic Engineering \\ The University of Nottingham \\ Nottingham, U.K. \\ luca.rovere@nottingham.ac.uk
}

\author{
Andrea Cassia, Mario Marchesoni \\ Dipartimento di Ingegneria Navale, Elettrica, Elettronica e \\ delle Telecomunicazioni - DITEN \\ Università degli Studi di Genova, \\ Genoa, Italy
}

\begin{abstract}
This paper presents the design and control of a three-phase ground power supply unit for aircraft servicing. A new mixed technology converter composed by a three-phase Silicon Carbide (SiC) full bridge unit and a three-phase full bridge IGBT unit connected across the same de link is used instead of the conventional full bridge configuration. In order to satisfy the stringent requirements of the output voltage quality particular attention is given to the controller. The common de link topology of the converter allows circulation of Zero Sequence Current (ZSC), therefore also a 0 axis regulator is necessary. The state space model of the system considering the LC output filter is presented and used in order to synthetize the controller parameters using the Optimal Control theory.
\end{abstract}

Keywords-Dual Inverter; Ground Power Unit; Silicon carbide technology; linear quadratic regulator

\section{INTRODUCTION}

In the past ground power supply units (GPUs) for aircraft both in military and civil aviation were built as a rotating motor-generator systems while nowadays the solid-state converter solution has been accepted as a standard due to higher efficiency, low maintenance, reduced costs and high reliability. The use of a solid-state converter GPU in an ac-toac back-to-back configuration coupled with an output LC filter leads to substantial savings since converting the energy burning fuel on the aircraft is more expensive than doing it on the ground. GPUs power ranges from 30 to $180 \mathrm{kVA}$ suppling aircrafts with a sinusoidal voltage of $115 \mathrm{Vrms}$ at $400 \mathrm{~Hz}$ [1]. Furthermore, the GPU is used in some cases for engine starting, allowing the shutdown of the auxiliary power unit (APU) on the aircraft and consequently reduce the air, noise pollution and maintenance of the APU. Of extreme importance is the voltage control of GPUs with output LC filter and isolation transformer, in order to achieve high quality output voltage regardless of type of load, without distortions even when feeding nonlinear loads such as diode bridge rectifiers and power electronic loads. Due to the stringent requirements conventional converters and controllers have difficulties to achieve good waveform quality [2-4] leading to application of more complex converter topologies such as multilevel converters [5] and matrix converters [6]. The most used methods to reduce harmonics and increase the voltage control performances consist in increasing the switching frequency or increasing the output filter [7]. The first solution encounters the problems of the limited switching capability of conventional semiconductor devices[8]. Instead increasing the values of the filter inductance and capacitance increases the quality of the output voltage, but increase the size and cost of the system and may lead to slow dynamic response. Since the dc link supply voltage is obtained rectifying the available network voltage of the airport a step down transformer is needed to provide the desired supply for the aircraft. The converter-side windings of the transformer can be then configured as an open-end. Applications of open-end winding (OEW) transformer are found in high-power converter systems connected to the medium-voltage network in order to match the voltage levels of the converter with the mediumvoltage grid. The OEW transformer can be fed from both ends using two-level voltage source inverters (VSIs)[9] achieving the same as a three-level neutral-point-clamped (NPC) converter. One single dc link or two separate ones can be used to feed the converters, in [10] separate dc links are used for a photovoltaic application while in [11] the same topology is used for a wind energy conversion system. The separate dc link architecture for the OEW transformer is well known in the literature and used with different converters topologies $[12,13]$. If on one hand choosing the common dc link topology results in a ZSC flowing freely in the system [14] on the other hand the common dc link structure significantly simplifies and reduces the costs of the topology. Different methods to suppress the ZSC have been proposed in the

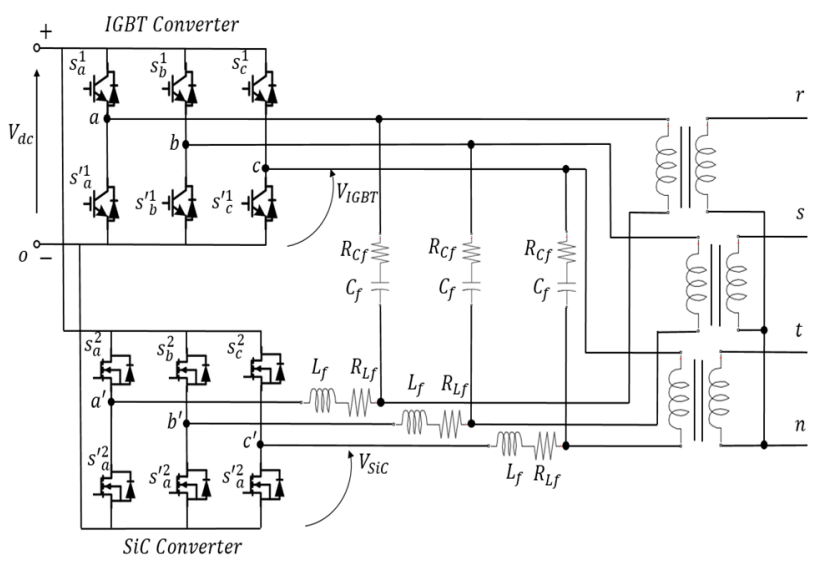

Fig. 1 Dual Fed IGBT-SiC GPU architecture 


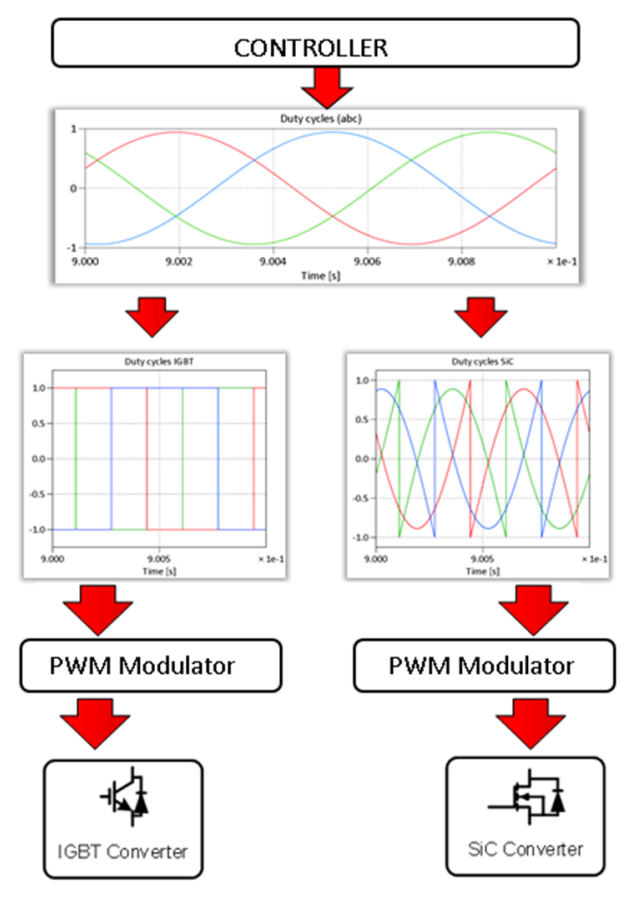

Fig. 2 Modulation scheme for Dual-Fed IGBT-SiC GPU

literature such as using CM chokes [9] or by implementing modified modulations [15-17]. In this paper, in order to achieve low harmonic distortion, two 2-level VSIs, one composed by IGBT devices and the other by $\mathrm{SiC}$ ones are used. Both the IGBT and $\mathrm{SiC}$ units of the converter are supplied by a common dc link supply. The SiC switching devices allow to work at higher switching frequencies than the conventional IGBTs with lower switching losses. However, due to their lower maturity level, the current rating of $\mathrm{SiC}$ products actually available on the market makes their use difficult in conjunction with IGBT, in high power applications. The double fed OEW transformer with common dc link architecture allows to double the supply voltage that means, for constant power, to halve the current. In this paper a new mixed technology composed of two converters, IGBT and $\mathrm{SiC}$, feeding three single phase transformers is used in order to obtain higher system efficiency [18] and reduce the harmonic distortion due to nonlinear loads. From the control point of view, one of the main disadvantages of working at $400 \mathrm{~Hz}$ is a reduced ratio between the switching frequency of the converter and the fundamental frequency, furthermore having the constraint of high control bandwidth in order to meet output voltage control requirements. Allowing the $\mathrm{SiC}$ unit to switch at higher frequencies than the IGBTs the previous problems are easily eliminated and compensation of high order harmonics is possible. Thanks to the output filter inductance and the transformer one, the zero sequence impedance is high enough to prevent the circulation of high ZSC, but still it requires a 0 -axis regulator. Consequently the controller adopted in this paper is composed by three integral controllers, one for each axis in the qd0 synchronous reference

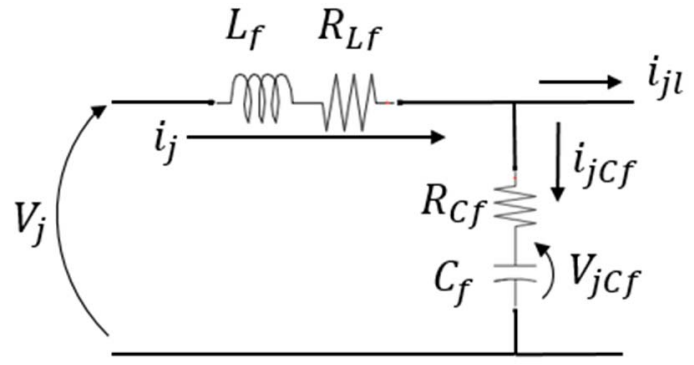

Fig. 3 Phase output filter

frame and two resonant controllers opportunely tuned for the $\mathrm{q}$ and $d$ axis respectively in order to eliminate the $5^{\text {th }}$ and $7^{\text {th }}$ harmonics introduced, for example, by a diode bridge rectifier. In presence of relatively complex regulator like the one adopted in this work, the tuning of the controller parameters can be difficult often resulting in unstable solution. To overcome this problem, the optimal control theory has been applied to synthetize the controller, resulting in very good performance. In the following, the system structure and model, the controller tuning procedure and some simulation results are reported.

\section{DuAl-Fed IGBT SiC Modulation AND CONTROL}

\section{A. Modulation scheme for Dual-Fed IGBT-SiC GPU}

The modulation consists in a square wave control of the IGBT converter allowing it to switch at the fundamental frequency being here $400 \mathrm{~Hz}$. The $\mathrm{SiC}$ converter instead, switches faster than the IGBT one in order to compensate the harmonic distortion introduced by the low switching-rate IGBT converter. This separation of the duty cycles between the two converters results in an increased efficiency of the overall architecture and allows to exploit the different natures of the two converters. Considering the different switching frequencies of the two converters, the IGBT is mainly responsible for the conduction losses while the $\mathrm{SiC}$ for the switching losses. The modulation adopted has been already applied for an open end winding permanent magnet synchronous drive [19] while in this paper it has been used for the OEW transformer GPU topology. The flowchart of the proposed modulation strategy is shown in Fig. 2. From Fig. 1 it is clear how the voltage on the output filter is the difference between the IGBT converter output voltage and the $\mathrm{SiC}$ one.

$$
V_{\text {Filter }}=V_{I G B T}-V_{S i C}
$$

In the dual-fed single dc-link configuration the maximum and minimum voltage that can be applied to each phase of the output filter are $V_{d c}$ and $-V_{d c}$ respectively, compared to $V_{d c} / 2$ and $-V_{d c} / 2$ of a standard single VSI. The modulation duty cycles are obtained normalising the controller output 
waveforms with respect to $V_{d c}$. The new modulation technique proposed is based on the voltage equation (1), in fact the same relationship is used for the duty cycles generation for the IGBT and $\mathrm{SiC}$ converters that will be fed to the modulators

$$
d_{a b c}=d_{I G B T}-d_{S i C}
$$

Where $d_{a b c}$ are the duty cycles corresponding to the normalised controller output control voltages, $d_{I G B T}$ and $d_{S i C}$ are respectively the duty cycles of the IGBT and $\mathrm{SiC}$ converters. As already mentioned, the aim is to exploit the two different technologies used for the two converters with the intent to reduce the overall converter losses, therefore the IGBT modules switch at the lowest possible switching frequency while the $\mathrm{SiC}$ is intended to switch as fast as possible. Setting the IGBT converter to modulate in six-step mode, i.e., square wave mode at the fundamental frequency of the output waveforms, would result in extremely low switching frequency and almost exclusively conduction losses for the IGBT switching devices. The IGBT duty cycles are then obtained from the controller ones as follows

$$
d_{I G B T}=0.5 \operatorname{sign}\left(d_{a b c}\right)
$$

From (3) the IGBT duties consist in 3 square waveforms of amplitude 0.5 with the same phase displacement of the 3 modulating $d_{a b c}$ signals. The modulating signals for the $\mathrm{SiC}$ converter are obtained from (2) knowing that the IGBT ones are expressed by (3) as

$$
d_{\text {SiC }}= \begin{cases}\left(0.5-d_{a b c}\right) & \text { if } d_{a b c}>0 \\ \left(-0.5-d_{a b c}\right) & \text { if } d_{a b c}<0\end{cases}
$$

The modulation described in (2-4) consists in a square wave control of the IGBT converter resulting in a switching frequency at the fundamental frequency of the grid. The square wave modulation of the IGBT converter introduces elevated harmonic distortion therefore the $\mathrm{SiC}$ converter needs to switch faster than the IGBT one in order to compensate it. The role of the $\mathrm{SiC}$ converter in this configuration can be interpreted as an active filter that eliminates the harmonic distortion introduced by the low switching IGBT one. This separation of the duty cycles between the two converters results in an increased efficiency of the overall architecture and allows to exploit the different natures of the two converters. Considering the different switching frequencies of the two converters, the IGBT is mainly responsible for the conduction losses while the $\mathrm{SiC}$ for the switching losses.

\section{B. Suppression of Zero-Sequence Current in Dual-Fed IGBT $\mathrm{SiC} \mathrm{GPU}$}

It is well known how OEW dual fed topologies sharing the same dc link have the intrinsic problem of circulating currents and their causes have been identified in the common mode voltage produced by the two converters and the voltage nonlinearities of a VSI such as dead-times and devices voltage drops [14]. The entity of the circulating current depends on the zero-sequence impedance of the topology: the lower the equivalent impedance the higher will be the ripple of the zerosequence current. In the topology proposed the problem of the circulating current is significantly reduced thanks to the output LC filter, of which its primary role is to filter out the high frequency distortion introduced by the converters in order to meet the output voltage requirements. As it will be shown in section II.C, combining the LC filter with a zero sequence controller allows to eliminate the circulating current.

\section{Control of Dual-Fed IGBT-SiC GPU}

It can be noticed that the 3 phases of the system depicted in Fig. 1 are identical, therefore the output filter of the single phase is sufficient in order to derive the three phase model of the system. For further explanation and notation the output filter is presented in Fig. 3 for a generic phase $j$, where $j$ can assume the values $a, b$ and $c$. If the Kirchhoff voltage and current equations are written for the system of Fig. 3, the following system is obtained:

$$
\left\{\begin{array}{c}
V_{j}=R_{L f} i_{j}+L_{f} \frac{d i_{j}}{d t}+R_{C f} i_{j C f}+V_{j C f} \\
i_{j C f}=C_{f} \frac{d V_{j C f}}{d t} \\
i_{j}=i_{j C f}+i_{j l}
\end{array}\right.
$$

Where $V_{j}$ are the equivalent voltages applied by the two inverters and $V_{j C f}$ are the filter capacitor voltages. $i_{j}, i_{j C f}$ and $i_{j l}$ are respectively the phase current, the current flowing on the filter capacitor and the load current absorbed. $L_{f}, R_{L f}, C_{f}, R_{C f}$ are respectively the output filter inductance and its equivalent series resistance, the filter capacitance and its equivalent series resistance. Rearranging equations (5) and writing them for the three phase system, equations (6) and (7) are obtained. 


$$
\begin{aligned}
& {\left[\begin{array}{l}
V_{a a^{\prime}} \\
V_{b b^{\prime}} \\
V_{c c^{\prime}}
\end{array}\right]} \\
& =\left[\begin{array}{ccc}
R_{L f}+R_{C f} & 0 & 0 \\
0 & R_{L f}+R_{C f} & 0 \\
0 & 0 & R_{L f}+R_{C f}
\end{array}\right]\left[\begin{array}{c}
i_{a} \\
i_{b} \\
i_{c}
\end{array}\right] \\
& +\left[\begin{array}{ccc}
L_{f} & 0 & 0 \\
0 & L_{f} & 0 \\
0 & 0 & L_{f}
\end{array}\right] \frac{d}{d t}\left[\begin{array}{l}
i_{a} \\
i_{b} \\
i_{c}
\end{array}\right] \\
& -\left[\begin{array}{ccc}
R_{C f} & 0 & 0 \\
0 & R_{C f} & 0 \\
0 & 0 & R_{C f}
\end{array}\right]\left[\begin{array}{l}
i_{a l} \\
i_{b l} \\
i_{c l}
\end{array}\right]+\left[\begin{array}{c}
V_{a C f} \\
V_{b C f} \\
V_{c C f}
\end{array}\right] \\
& {\left[\begin{array}{l}
i_{a} \\
i_{b} \\
i_{c}
\end{array}\right]=\left[\begin{array}{ccc}
C_{f} & 0 & 0 \\
0 & C_{f} & 0 \\
0 & 0 & C_{f}
\end{array}\right] \frac{d}{d t}\left[\begin{array}{l}
V_{a C f} \\
V_{b C f} \\
V_{c C f}
\end{array}\right]+\left[\begin{array}{l}
i_{a l} \\
i_{b l} \\
i_{c l}
\end{array}\right]}
\end{aligned}
$$

Finally, the system equations are transformed in the qd0 synchronous reference frame resulting in

$$
\left\{\begin{array}{c}
\dot{\boldsymbol{x}}_{p}=A_{p} \boldsymbol{x}_{p}+B_{p} \boldsymbol{u}_{p}+D_{p} \boldsymbol{d} \\
\boldsymbol{y}_{p}=C_{p} \boldsymbol{x}_{p}
\end{array}\right.
$$

The qd0 system matrices and vectors are reported at the bottom of the page for clarity of explanation. $\omega_{0}$ is the grid pulsation, $\boldsymbol{x}_{p}$ are the system state, $\boldsymbol{d}$ are the load disturbance currents, $\boldsymbol{y}_{p}$ represent the system states that want to be controlled to a set point and $\boldsymbol{u}_{p}$ the system input corresponding to the transformed voltages produced by the inverters. The final goal of the controller is to regulate the 3 capacitor voltages to their reference values and rejecting at the same time the load disturbances. A convenient way to synthetize it is to use a linear quadratic approach [20]. Given a system in the state space form (8), the optimal linear quadratic regulator permits to compute a feedback control law in the form

$$
\boldsymbol{u}_{p}=-K_{p} \boldsymbol{x}_{p}
$$

minimizing the cost

$$
J_{p}=\int_{0}^{\infty} \boldsymbol{x}_{p}{ }^{\prime} Q_{p} \boldsymbol{x}_{p}+\boldsymbol{u}_{p}{ }^{\prime} R_{p} \boldsymbol{u}_{p} d t
$$

However, the presence of a distorting load (i.e. a diode bridge rectifier) would cause the presence of a load current no longer sinusoidal, which is the main constraint that a GPU has to satisfy. Typically, the current distortions produced by a nonlinear load appear at frequencies multiple of $5 \omega_{0}$ and $7 \omega_{0}$ which correspond to a sixth harmonic $\left(6 \omega_{0}\right)$ in the $\mathrm{qd} 0$ reference frame. In many applications, compensating for the $6^{\text {th }}$ harmonic is sufficient to obtain good output waveforms. An elegant way to face the problem is to filter the relevant portion of system state using a dynamic system presenting high gain at the frequencies to be compensated. The output of the filter will be then used in the cost function (10) in place of the whole state. In this work, the dc component and the $6^{\text {th }}$ harmonic are the most relevant. The $6^{\text {th }}$ harmonic filter has been added in parallel to the integral controller only for the $q$ and $d$ axis because exclusively on these axis the distortion is present. The overall filter state space structure is

$$
\begin{gathered}
\left\{\begin{array}{l}
\dot{\boldsymbol{x}}_{c}=A_{c} \boldsymbol{x}_{c}+B_{c} \boldsymbol{u}_{c} \\
\boldsymbol{y}_{c}=C_{c} \boldsymbol{x}_{c}
\end{array}\right. \\
A_{c}=\left[\begin{array}{ccc}
A_{c 1} & \mathbf{0} & \mathbf{0} \\
\mathbf{0} & A_{c 1} & \mathbf{0} \\
\mathbf{0} & \mathbf{0} & A_{c 2}
\end{array}\right] B_{c}=\left[\begin{array}{ccc}
B_{c 1} & \mathbf{0} & \mathbf{0} \\
\mathbf{0} & B_{c 1} & \mathbf{0} \\
\mathbf{0} & \mathbf{0} & B_{c 2}
\end{array}\right] \\
C_{c}=\left[\begin{array}{ccc}
C_{c 1} & \mathbf{0} & \mathbf{0} \\
\mathbf{0} & C_{c 1} & \mathbf{0} \\
\mathbf{0} & \mathbf{0} & C_{c 2}
\end{array}\right]
\end{gathered}
$$

$$
\begin{aligned}
& A_{p}=\left[\begin{array}{cccccc}
-\frac{R_{L f}+R_{C f}}{L_{f}} & -\frac{1}{L_{f}} & -\omega_{0} & 0 & 0 & 0 \\
\frac{1}{C_{f}} & 0 & 0 & -\omega_{0} & 0 & 0 \\
\omega_{0} & 0 & -\frac{R_{L f}+R_{C f}}{L_{f}} & -\frac{1}{L_{f}} & 0 & 0 \\
0 & \omega_{0} & \frac{1}{C_{f}} & 0 & 0 & 0 \\
0 & 0 & 0 & 0 & -\frac{R_{L f}+R_{C f}}{L_{f}} & -\frac{1}{L_{f}} \\
0 & 0 & 0 & 0 & \frac{1}{C_{f}} & 0
\end{array}\right] \quad B_{p}=\left[\begin{array}{cccc}
\frac{1}{L_{f}} & 0 & 0 \\
0 & 0 & 0 \\
0 & \frac{1}{L_{f}} & 0 \\
0 & 0 & 0 \\
0 & 0 & \frac{1}{L_{f}} \\
0 & 0 & 0
\end{array}\right] \quad\left[\begin{array}{ccc}
\frac{R_{C f}}{L_{f}} & 0 & 0 \\
-\frac{1}{C_{f}} & 0 & 0 \\
0 & \frac{R_{C f}}{L_{f}} & 0 \\
0 & -\frac{1}{C_{f}} & 0 \\
0 & 0 & \frac{R_{C f}}{L_{f}} \\
0 & 0 & -\frac{1}{C_{f}}
\end{array}\right]
\end{aligned}
$$

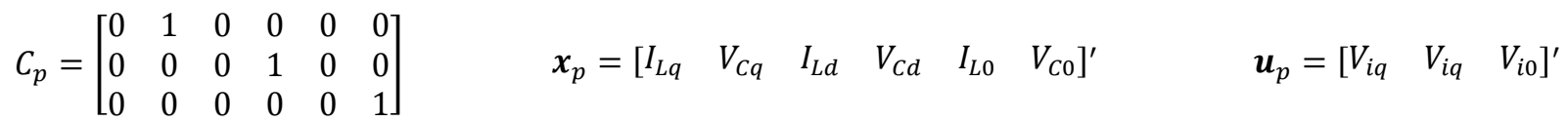


where

$$
\begin{gathered}
A_{c 1}=\left[\begin{array}{ccc}
0 & 1 & 0 \\
-\omega_{c}^{2} & 0 & 0 \\
0 & 0 & 0
\end{array}\right], B_{c 1}=\left[\begin{array}{c}
0 \\
\omega_{c}^{2} \\
1
\end{array}\right] \\
C_{c 1}=\left[\begin{array}{lll}
1 & 0 & 0 \\
0 & 0 & 1
\end{array}\right], \quad A_{c 2}=0, \quad B_{c 2}=1, \quad C_{c 2}=1
\end{gathered}
$$

All the $\mathbf{0}$ terms are null matrices of appropriate dimension. $\boldsymbol{x}_{c} \in \Re^{7}, \boldsymbol{u}_{c} \in \Re^{3}$ and $\boldsymbol{y}_{c} \in \Re^{3}$ are the state, the input and the output of the filter respectively. $\omega_{c}$ is the resonance pulsation of the filter. A resonant-integral filter has been used for the dand q-axis while an integral filter has been adopted for the 0 axis. Extending system (8) with filter (11) considering that $\boldsymbol{u}_{c}=\boldsymbol{y}_{p}$

$$
\begin{gathered}
\left\{\begin{array}{c}
\dot{\boldsymbol{x}}=A \boldsymbol{x}+B \boldsymbol{u} \\
\boldsymbol{y}=C \boldsymbol{x}
\end{array}\right. \\
A=\left[\begin{array}{cc}
A_{p} & \mathbf{0} \\
B_{c} C_{p} & A_{c}
\end{array}\right] B=\left[\begin{array}{c}
B_{p} \\
\mathbf{0}
\end{array}\right] C=\left[\begin{array}{ll}
\mathbf{0} & C_{c}
\end{array}\right]
\end{gathered}
$$

$\boldsymbol{x}=\left[\begin{array}{ll}\boldsymbol{x}_{p} & \boldsymbol{x}_{c}\end{array}\right]^{\prime}$ is the state, $\boldsymbol{u} \in \mathfrak{R}^{3}$ is the input and $\boldsymbol{y} \in \mathfrak{R}^{3}$ is the performance output. Equations (9) and (10) are adapted to system (14) resulting in

$$
\begin{gathered}
\boldsymbol{u}=-K \boldsymbol{x} \\
J=\int_{0}^{\infty} \boldsymbol{y}^{\prime} Q \boldsymbol{y}+\boldsymbol{u}^{\prime} R \boldsymbol{u} d t
\end{gathered}
$$

The controller output voltages are then split into the two converter voltage references as explained before. Since the control law (15) is now a static feedback from the extended system state, the resulting controller is a dynamic regulator

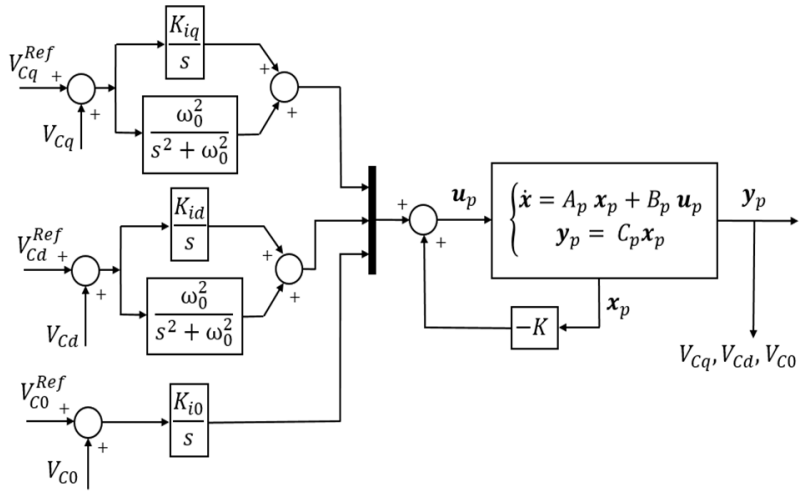

Fig. 4 System control structure
TABLE I

SIMULATION PARAMETERS

\begin{tabular}{|c|c|c|c|}
\hline Name & Description & Value & Unit \\
\hline$L_{f}$ & Filter inductance & 250 & {$[\mu \mathrm{H}]$} \\
\hline$R_{L f}$ & $\begin{array}{c}\text { Longitudinal filter } \\
\text { Resistance }\end{array}$ & 0.005 & {$[\Omega]$} \\
\hline$C_{f}$ & Filter capacitance & 25 & {$[\mu \mathrm{F}]$} \\
\hline$R_{C f}$ & $\begin{array}{c}\text { Transversal filter } \\
\text { Resistance }\end{array}$ & 0.005 & {$[\Omega]$} \\
\hline$V_{c c} \%$ & $\begin{array}{c}\text { Short circuit transformer } \\
\text { Voltage }\end{array}$ & $2 \%$ & - \\
\hline$V_{d c}$ & Dc link Voltage & 600 & {$[\mathrm{~V}]$} \\
\hline$q_{r}$ & $\begin{array}{c}\text { Resonant controller } \\
\text { weight }\end{array}$ & $10^{9}$ & - \\
\hline$q_{i}$ & $\begin{array}{c}\text { Integral controller } \\
\text { weight }\end{array}$ & $10^{10}$ & - \\
\hline & $\quad$ r \\
\hline
\end{tabular}
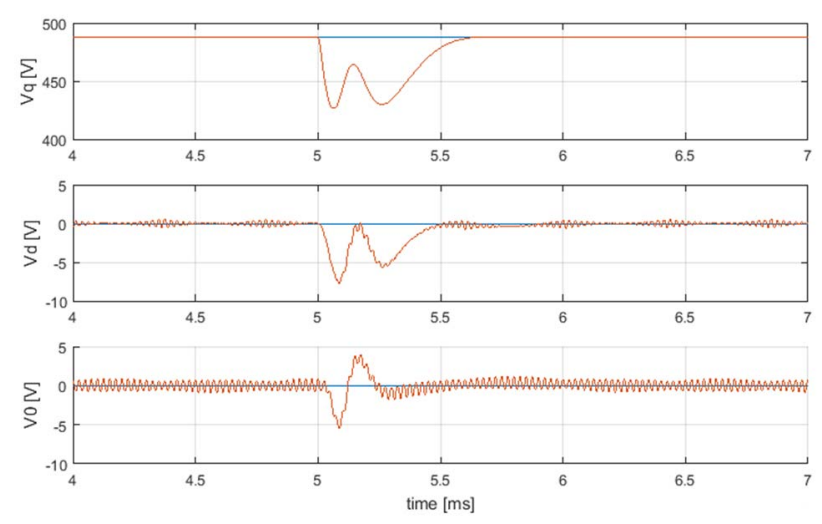

Fig. 5 Voltage transient with load step at $5 \mathrm{~ms}$ from $10 \%$ to full rated power. Top: reference $\mathrm{Vq}$ (blue) and $\mathrm{Vq}$ (red). Middle: reference Vd (blue) and Vd (red). Bottom: reference V0 (blue) and V0 (red)

including the filter dynamics (11). The resulting overall control structure is presented in Fig. 4.

\section{Simulation RESUltS}

The performance of the proposed GPU has been tested in simulation using MatlablSimulink. The main system parameters are reported in Table I. The weights $Q$ and $R$ of (16) are square matrices of null elements outside the diagonal. $Q$ has all one on the main diagonal while $R$ has all zeros except the elements corresponding to the resonant and integral states. The values used in the simulation are reported in Table I The voltage references for the $\mathrm{d}$ - and 0 - axis are set to zero while the q-axis voltage reference is set to be 3 times the output voltage since step down transformers with a transformation ratio of 3 are used. Fig. 5 presents the results obtained with a three-phase resistive load, the actual voltages compared against their reference values in the qd0 reference frame when a load step from $10 \%$ to full load is applied at 5 ms. Fig. 6 shows the qd0 voltage transients when a nonlinear diode bridge rectifier load is connected at $4 \mathrm{~ms}$. The ripple 

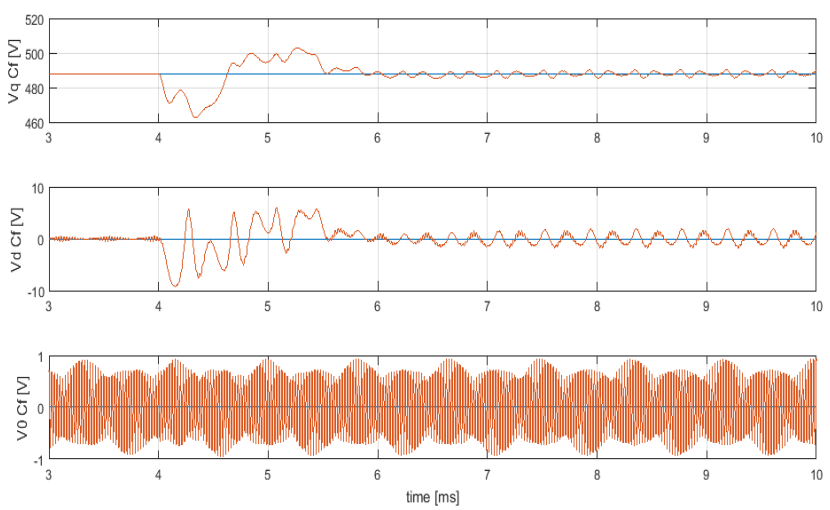

Fig. 6 Voltage transient when a nonlinear load is connected at $4 \mathrm{~ms}$. Top: reference $\mathrm{Vq}$ (blue) and $\mathrm{Vq}$ (red). Middle: reference $\mathrm{Vd}$ (blue) and $\mathrm{Vd}$ (red). Bottom: reference V0 (blue) and V0 (red)

could be further reduced extended filter (11) with additional resonance peak at other frequencies. Fig. 7 shows the effectiveness of the implemented control in tracking the output reference voltage with a negligible error. The THD is evaluated as $1.81 \%$ far below the standards limit of $5 \%$.

\section{CONCLUSIONS}

A new IGBT-SiC dual fed three-phase ground power unit architecture for aircraft servicing has been presented. The system composed by a novel mixed technology IGBT-SiC converter with the two units connected across the same dc link with an output LC filter and three single phase transformers has been mathematically analyzed. A system model has been derived and used to synthetize the controller with the linear quadratic regulator. High performance both in dynamics and harmonic distortion elimination for the case of a nonlinear bridge rectifier load has been achieved as shown in the simulation results.

\section{REFERENCES}

P. Zanchetta, J. C. Claire;, and P. W. Wheeler;, "Control of static frequency changers for aircraft ground power supplies with stringent performance requirements," Proc. EPE Conf., Toulouse, France, Sep. 2003.

[2] U. B. Jensen;, F. Blaabjerg;, and J. K. Pedersen;, "A new control method for $400-\mathrm{Hz}$ ground power units for airplanes," IEEE Trans. Ind. Appl., vol. vol. 36, no. no. 1, pp. pp. 180-187, Jan./Feb. 2000.

[3] M. Abarzadeh, H. M. Kojabadi, and L. Chang, "A modified static ground power unit based on active natural point clamped converter," Proc. IEEE Energy Convers. Congr. Expo., pp. pp. 3508-3514, 2015.

[4] C. Liu;, C. Sun;, and W.Hu;, "Proportional-resonant controller of high power $400 \mathrm{~Hz}$ inverter in stationary frame," Proc. Int. Conf. Elect. Mach. Syst., vol. vol. 1, pp. pp. 1772-1777, 2008.

[5] M. Abarzadeh;, and H. M. Kojabadi;" "A Static Ground Power Unit Based on the Improved Hybrid Active Neutral-Point-Clamped Converter," IEEE Trans. Ind Electr., vol. vol. 63, no. no. 12, Dec. 2016.

[6] S. L. Arevalo, P. Zanchetta, P. W. Wheeler, A. Trentin, and L. Empringham, "Control and Implementation of a Matrix-ConverterBased AC Ground Power-Supply Unit for Aircraft Servicing," IEEE Trans. Ind Electr., vol. vol. 57, no. no. 6, pp. Jun, 2010.
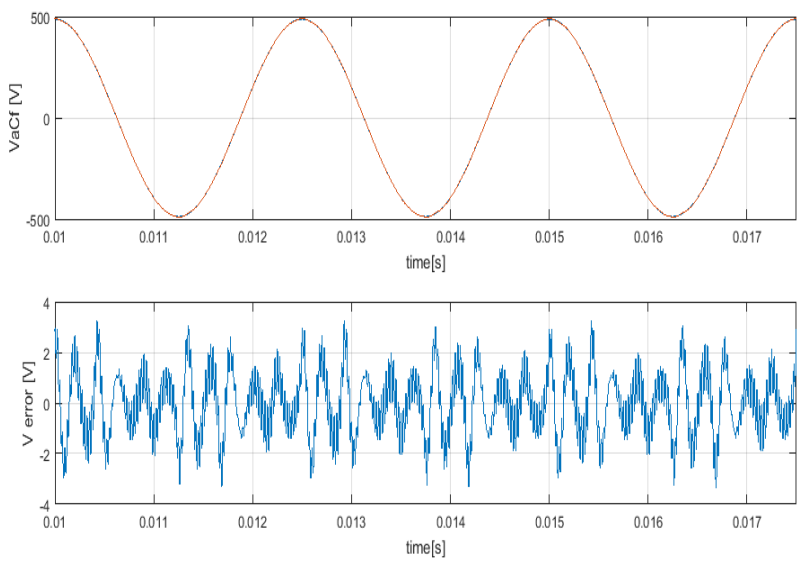

Fig. 7 Top: Output voltage (blue) and voltage reference (red) in phase a. Bottom: error between the reference and the output voltage.

IEEE Trans. Power Electron., vol. vol. 28, no. no. 1, pp. pp. 408417, Jan. 2013.

[8] K. Fujii, P. Koellensperger, and R. W. D. Doncker, "Characterization and comparison of high blocking voltage IGBTs and IEGTs under hard- and soft-switching conditions," IEEE Trans. Power Elect., vol. 23, no. 1, pp. 172-179, Jan. 2006.

[9] H. Stemmler, and P. Guggenbach, "Configurations of high-power voltage source inverter drives," in Proc. EPE Conf., 1993, pp. 7 14.

[10] G. Grandi, C. Rossi, D. Ostojic, and D. Casadei, “A New Multilevel Conversion Structure for Grid-Connected PV Applications," IEEE Trans. Ind Electr., vol. 56, no. 11, pp. 44164426, 2009.

[11] E. Levi, "Multiphase Electric Machines for Variable-Speed Applications," IEEE Transactions on Industrial Electronics, vol. 55, no. 5, pp. 1893-1909, 2008.

[12] G. Gohil, L. Bede, R. Teodorescu, T. Kerekes, and F. Blaabjerg, "Optimized Integrated Harmonic Filter Inductor for DualConverter-Fed Open-End Transformer Topology," IEEE Trans. Ind Electr., vol. 32, no. 3, pp. 1818-1831, 2017.

[13] G. Gohil, L. Bede, R. Teodorescu, T. Kerekes, and F. Blaabjerg, "Dual-Converter-Fed Open-End Transformer Topology With Parallel Converters and Integrated Magnetics," IEEE Trans. Ind Electr., vol. 63, no. 8, pp. 4929-4941, 2016.

[14] A. Somani, R. K. Gupta, K. K. Mohapatra, and N. Mohan, "On the Causes of Circulating Currents in PWM Drives With Open-End Winding AC Machines," IEEE Trans. on Industrial Electronics, vol. 60 , no. 9 , pp. 3670 - 3678, Sept. 2013.

[15] N. Bodo, M. Jones, and E. Levi, "A Space Vector PWM With Common-Mode Voltage Elimination for Open-End Winding FivePhase Drives With a Single DC Supply," IEEE Trans. Ind Electr., vol. 61, no. 5, pp. 2197-2207, 2014.

[16] M. R. Baiju, K. K. Mohapatra, R. S. Kanchan, and K. Gopakumar, "A dual two-level inverter scheme with common mode voltage elimination for an induction motor drive," IEEE Trans. Power Elect., vol. 19, no. 3, pp. 794-805, 2004.

[17] V. T. Somasekhar, S. Srinivas, and K. K. Kumar, "Effect of ZeroVector Placement in a Dual-Inverter Fed Open-End Winding Induction-Motor Drive With a Decoupled Space-Vector PWM Strategy," IEEE Trans. Ind Electr., vol. 55, no. 6, pp. 2497-2505, 2008.

[18] G. Lo Calzo, P. Zanchetta, C. Gerada, A. Gaeta, and F. Crescimbini, "Converter topologies comparison for more electric aircrafts high speed Starter/Generator application," in IEEE Energy Conversion Congress and Exposition (ECCE), Montreal, QC, 2015.

[19] L. Rovere, A. Cassia, A. Formentini, G. L. Calzo, P. Zanchetta, and M. Marchesoni, "IGBT-SiC Dual Fed Open End Winding PMSM Drive," in IEMDC, Miami, 2017. 
[20] B. D. O. Anderson;, and J. B. Moore;, "Optimal Control: Linear Quadratic Methods," Prentice Hall, Englewood Cliffs, New Jersey, 